Western University Scholarship@Western

Aboriginal Policy Research Consortium International (APRCi)

2006

\title{
Indigenous Suicide in New Zealand
}

Annette L. Beautrais

David M. Fergusson

Follow this and additional works at: https://ir.lib.uwo.ca/aprci

Part of the Medicine and Health Commons, and the Other Mental and Social Health Commons

Citation of this paper:

Beautrais, Annette L. and Fergusson, David M., "Indigenous Suicide in New Zealand" (2006). Aboriginal Policy Research Consortium International (APRCi). 185.

https://ir.lib.uwo.ca/aprci/185 
This article was downloaded by: [University of Western Ontario]

On: 18 November 2012, At: 06:36

Publisher: Routledge

Informa Ltd Registered in England and Wales Registered Number: 1072954 Registered office: Mortimer House, 37-41 Mortimer Street, London W1T 3J H, UK

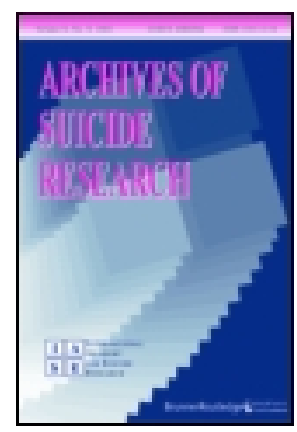

\title{
Archives of Suicide Research
}

Publication details, including instructions for authors and subscription information:

http:// www. tandfonline.com/loi/ usui20

\section{Indigenous Suicide in New Zealand}

\author{
Annette L. Beautrais ${ }^{a} \&$ David M. Fergusson ${ }^{b}$ \\ ${ }^{a}$ Canterbury Suicide Project, Christchurch School of Medicine \& \\ Health Sciences, Christchurch, New Zealand \\ ${ }^{b}$ Christchurch Health and Development Study, Christchurch \\ School of Medicine and Health Sciences, Christchurch, New \\ Zealand \\ Version of record first published: 15 Aug 2006.
}

To cite this article: Annette L. Beautrais \& David M. Fergusson (2006): Indigenous Suicide in New Zealand, Archives of Suicide Research, 10:2, 159-168

To link to this article: http:// dx.doi.org/ 10.1080/ 13811110600556913

\section{PLEASE SCROLL DOWN FOR ARTICLE}

Full terms and conditions of use: http://www.tandfonline.com/page/terms-andconditions

This article may be used for research, teaching, and private study purposes. Any substantial or systematic reproduction, redistribution, reselling, loan, sub-licensing, systematic supply, or distribution in any form to anyone is expressly forbidden.

The publisher does not give any warranty express or implied or make any representation that the contents will be complete or accurate or up to date. The accuracy of any instructions, formulae, and drug doses should be independently verified with primary sources. The publisher shall not be liable for any loss, actions, claims, proceedings, demand, or costs or damages whatsoever or howsoever caused arising directly or indirectly in connection with or arising out of the use of this material. 


\title{
Indigenous Suicide in New Zealand
}

\author{
Annette L. Beautrais and David M. Fergusson
}

\begin{abstract}
This article describes patterns of suicide and attempted suicide among the indigenous (Māori) population of New Zealand using official data from the New Zealand Health Information Service (NZHIS). The majority of Maiori suicides (75\%) occurr in young people aged $<35$ years. Rates of suicide are higher among Māori males and females aged $<25$ than in their non-Mäori peers. Rates of hospitalization for attempted suicides are higher amongst Māori males aged 15-24, compared to non-Māori. In contrast, suicide is virtually unknown amongst older Māori (60 years). This article reviews explanations for the observed rates of suicide in Māori, and examines approaches to effective intervention to reduce rates of suicide in young Māori.
\end{abstract}

Keywords suicide, indigenous, New Zealand, Māori

New Zealand has a population of approximately 4 million citizens (www.stats. govt.nz). Of these, 15\% (approximately $586,000)$ identify as Māori (indigenous) New Zealanders. The Māori population is relatively young with a median age of 22 years (compared to the median age of 35 for the total population) and has a projected growth of $28 \%$ by 2021 .

Rates of suicide in New Zealand show clear differences between the Māori and non-Māori populations. For example, Māori comprise $19 \%$ of the youth population aged 15-24 years (www.stats.govt.nz), but accounted for $35 \%$ of all youth suicides in 2002 (www.moh.govt.nz), the year for which most recent data are available. Compared to their non-Māori peers, Māori youth (males and females) are overrepresented in suicide and Māori males are over-represented in hospitalizations for suicide attempts. However, older Māori males and females appear to be protected from suicide when compared with their non-Māori counterparts (Beautrais, 2003; www.moh. govt.nz). Suicide is virtually unknown in Māori aged 60 and older, and is rare after age 45.

This article examines rates of suicidal behavior in New Zealand for the indigenous Māori population, reviews explanations that have been put forward to account for the observed rates, and considers approaches to effective intervention to reduce rates of suicidal behavior.

\section{Problems of Epidemiology}

In New Zealand, as a result of changes in the ways in which the ethnicity of those dying by suicide has been recorded, it is not possible to examine ethnic differences in suicide rates prior to 1995 (Ministry of Health, 2001; Statistics New Zealand, 1998). Until 1995 ethnicity was based upon an assessment of the individual's extent of Māori descent. Recognition of the limitations of this method of measurement led to a 
revision of data collection methods. Since 1995, ethnicity has been defined on the basis of self-report, or, for those who have died by suicide, the family's report of the individual's ethnic self-identification. This change in definitions has led to a clear discontinuity in time series data, and recognition that Māori suicide was likely to have been underenumerated prior to 1995 . For these reasons it is not possible to compare data prior to 1995 with data more recent than 1995 .

It has been suggested that indigenous suicide may be under-enumerated for a number of reasons including coroner's practices, and misclassification of ethnicity, method and death (Hunter \& Harvey, 2002). However, it is unlikely indigenous suicides in New Zealand are subject to these potential sources of bias, for a number of reasons. Firstly, all suspected suicide deaths in New Zealand are reported to a coroner and are subject to a coroner's inquest. To obtain information for the inquest and to exclude other reasons for the death, police investigate all suspected suicide deaths by asking questions from family members and associates about the death. Secondly, most suicides are accomplished by hanging, so there is usually no competing explanation for the death, and little chance for the death to be misclassified on the basis of method.

In addition, there have been recent suggestions that official statistics may underestimate Māori suicide rates in some age groups. Unpublished data from Māori researchers, using different approaches to defining Māori ethnicity and generating Māori population estimates, appear to yield suicide statistics for Māori which differ from official statistics (Pitama and Robertson, personal communication).

\section{METHOD}

For the purposes of this article, we use data for Māori and non-Māori suicides provided for official purposes by the New Zealand Health
Information Services (NZHIS) of the Ministry of Health.

\section{RESULTS}

\section{Māori and Non-Māori Suicide Rates}

Total Population. Figure 1 compares Māori and non-Māori suicide rates, for all ages, during the period 1996-2002. For both males and females, from 1996 through to 1998 Māori had higher rates of suicide than nonMāori, but since 1999 Māori rates have tended to converge to those of non-Māori. However, in 2002 Māori male (19.7 per 100,000) and female (5.9) rates remained higher than non-Māori rates (males 15.6, females 4.8). During the last seven years (1996-2002) suicide rates have tended to decline in both Māori males and females, consistent with trends for the total population.

\section{Youth Aged 15-24}

For Māori youth, suicide trends differ from those for the total Māori population. Both young male and female Māori have had higher rates of suicide than non-Māori each year from 1996 to 2002 (see Figure 2). Most recent data (2002) suggest that young Māori males (43.7 deaths per 100,000) and females (18.8) still have significantly higher rates of suicide than their non-Māori peers (males 18.0; females 9.1). These data suggest that young Māori males are almost 3 times more likely, and young Māori females are twice as likely, to die by suicide than nonMāori young people. Despite the elevated rates in Māori youth, in recent years their suicide rates have shown similar declines to non-Māori rates.

$$
\text { Older People }(60+\text { Years })
$$

Older Māori, male and female, appear to be protected from suicide, compared to their non-Māori peers and compared to younger Māori. In 2002, there were no suicides among Māori aged 60 and older. 


\section{Age-standardized rate (per 100,000)}

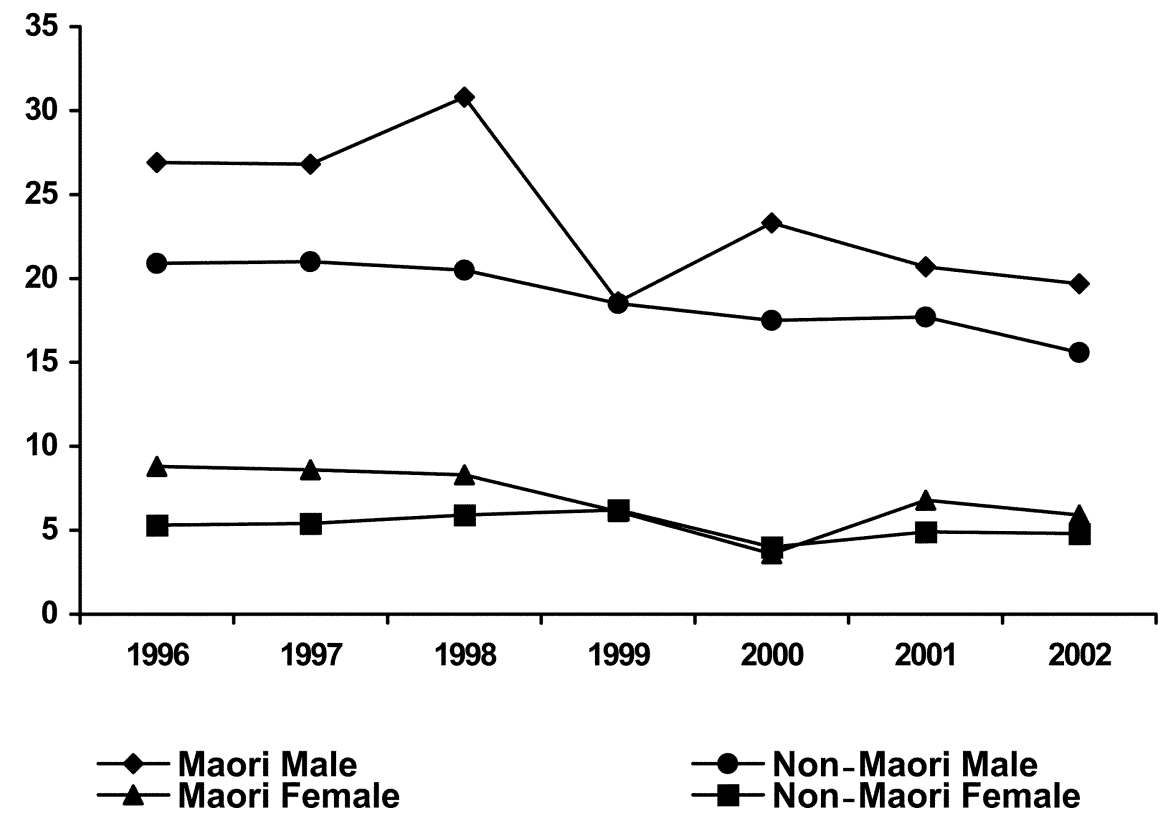

FIGURE 1. Mäori and non-Mäori suicide rates total population by gender 1996-2002.

Children and Very Young Adolescents (<15 Years)

The number of suicide deaths each year in children and very young adolescents aged less than 15 years is very small. A national study which aggregated data for this age group over a ten-year period found that Māori children and very young adolescents were at higher risk of suicide than their non-Māori peers (Beautrais, 2001). The majority (a disproportionate $57 \%$ ) of suicides in this age group were Māori. (Māori constitute $24 \%$ of the total population aged 5 to 14 ).

Taken together, the data suggest that most Māori suicide deaths tend to occur in younger people. Data for 2002 confirm this: $42 \%$ of Māori deaths by suicide occurred in young people aged 15 to 24 , and $75 \%$ occurred in young Māori aged $<35$ years. In comparison, $16 \%$ of all non-Māori suicides were aged 15 to 24 , and $37 \%$ of non-Māori suicides occurred in aged $<35$.

\section{Māori and Non-Māori Rates of Attempted Suicide}

Suicide attempts range from the medically minor to severe and not all suicide attempts require medical attention. Consequently data regarding admissions to hospital for attempted suicide significantly underestimate actual rates. Nevertheless, these data provide a useful measure of suicide attempts for which medical attention was sought. Figure 3 compares Māori and non-Māori rates of hospitalization for suicide and selfinflicted injury in 2001/2002 (hospitalization data are provided for financial years, from 1 July to end June).

For Māori, the hospitalization rate for suicide and self-inflicted injury was 116.6 admissions per 100,000 (719 cases). The rate of hospitalization for Māori males 


\section{Age-standardized rate (per 100,000)}

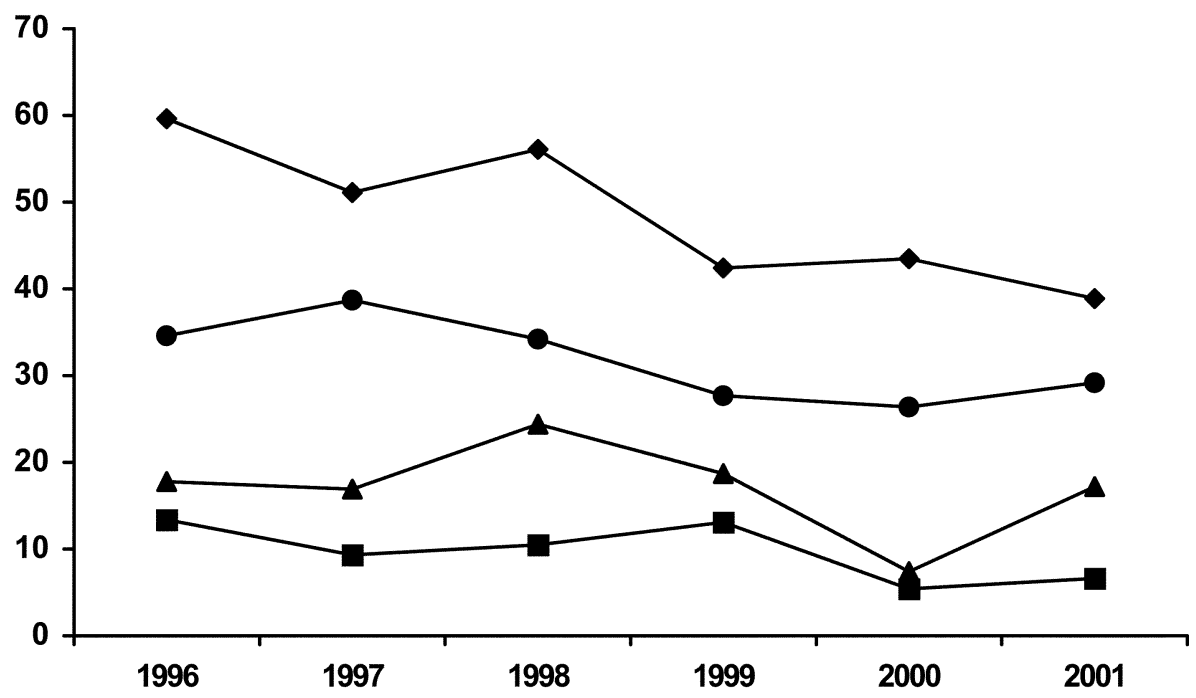

FIGURE 2. Mäori and non-Mäori youth (15-24 years) suicide rates by gender 1996-2002.

(100.6 cases per 100,000; 299 cases) was higher than that for non-Māori males (82.7 per 100,$000 ; 1,422$ cases). However, the hospitalization rate for Māori females was 132.1 cases per 100,000 (420 cases), less than the rate for non-Māori females (176.7 per 100,$000 ; 2,954$ cases).

These figures may be elaborated for youth aged 15 to 24. Young Māori males had higher hospitalization rates for attempted suicide for ages 15-19 (147.7 per 100,000; 41 cases) and from 20-24 years (275.3 per 100,$000 ; 65$ cases) than their non-Māori peers (15-19 years: 122 cases per 100,000, 139 cases; 20-24 years: 194.6 cases per 100,000; 204 cases). However, non-Māori females had higher rates of hospitalization for each youth age group (15-19 years: 468.3 cases per 100,000, 509 cases; 20-24 years: 408.5 per 100,000, 423 cases) than Māori females (15-19 years: 271.3 cases per 100,000,
75 cases; 20-24 years: 321.7 per 100,000, 79 cases). Additionally, hospitalization rates for attempted suicide for ages 15-19 (147.7 per 100,$000 ; 41$ cases) and from 20-24 years (275.3 per 100,000; 65 cases) than their non-Māori peers (15-19 years: 122 cases per 100,000, 139 cases; 20-24 years: 194.6 cases per 100,000; 204 cases). However, non-Māori females had higher rates of hospitalization for each youth age group (15-19 years: 468.3 cases per 100,000, 509 cases; 20-24 years: 408.5 per 100,000, 423 cases) than Māori females (15-19 years: 271.3 cases per $100,000,75$ cases; 20-24 years: 321.7 per $100,000,79$ cases).

\section{Self-Identification of Ethnicity}

Following the introduction of ethnic self-identification, Māori ethnicity has come to be defined in three ways: those 


\section{Age-standardized rate (per 100,000)}

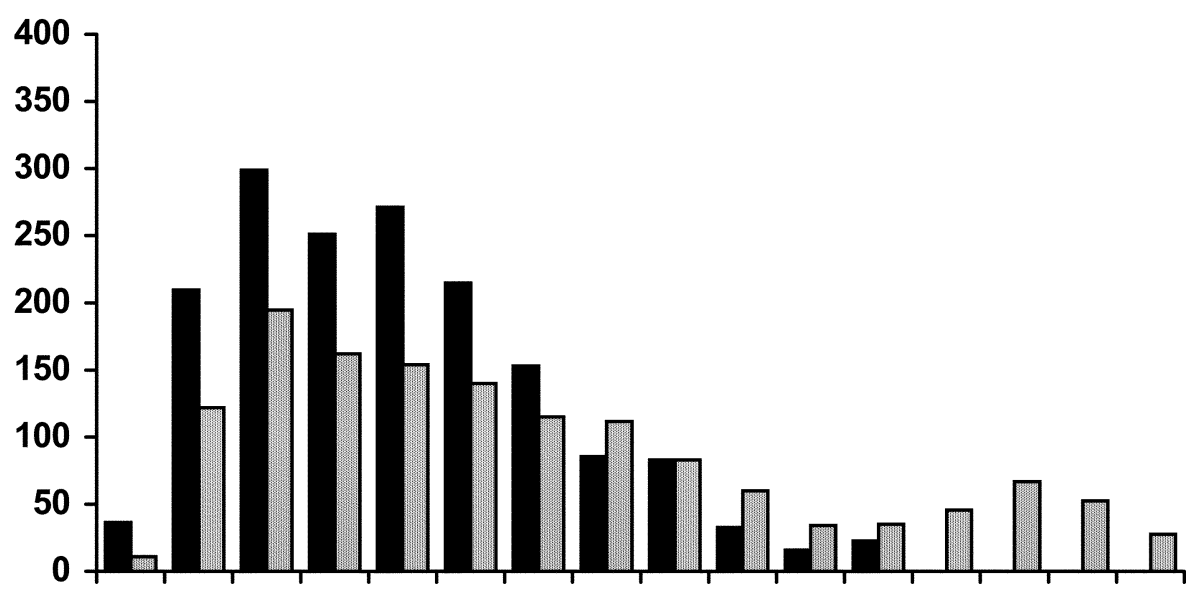

10- 15- 20- 25- 30- 35- 40- 45- 50- 55- 60- 65- 70- 75- 80- 85+ Age group

FIGURE 3. Suicide and self-inflicted injury bospitalization rate, for Māori and non-Māori males, 2001/2002.

who define themselves as solely Māori; those who acknowledge Māori ancestry or descent, and those who define themselves as Māori as one of multiple ethnic identifications (Robson \& Reid, 2000). There is some evidence that those who identify as solely Māori are more at risk of suicide, and of mental ill-health, than those who identify as having Māori ancestry or those who identify as Māori as one of multiple ethnic affiliations (Robson \& Reid, 2000).

\section{Ethnic Density}

There is also some evidence that Māori living in regions where a high proportion of the population are Māori have lower suicide rates than areas where smaller fractions of the population are Māori (Coupe, unpublished information). Similar data have been reported for a number of countries and support the argument that ethnic density protects against suicide (Neeleman, Wilson-Jones, \& Wessely, 2001).

Differences in Methods of Suicide

Comparisons of Māori and non-Māori methods of suicide have shown clear differences between the two populations (Beautrais, 2000). Māori suicides were significantly more likely to occur by hanging and significantly less likely to involve vehicle exhaust gas or firearms. This finding may reflect access to, and availability of, means of suicide.

\section{Welfare Services}

Māori young people who access national child welfare services have higher 


\section{Age-standardized rate (per 100,000)}

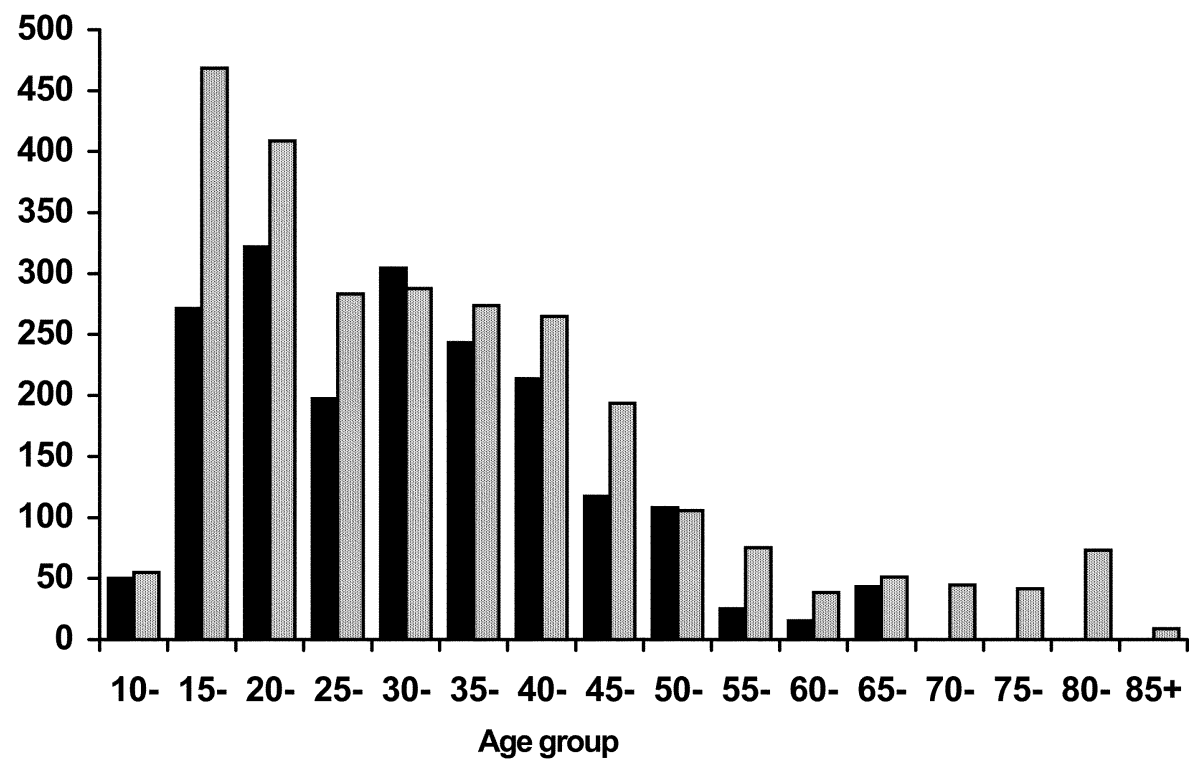

FIGURE 4. Suicide and self-inflicted injury hospitalization rate, for Māori and non-Māori females, 2001/2002.

rates of suicide than non-Māori who access these services (Beautrais, 2001; Beautrais, Ellis, \& Smith, 2001; Smith \& Beautrais, 1999). Among those in contact with welfare services, the risk of suicide is highest among young Māori females (Beautrais, Ellis, \& Smith, 2001).

\section{Prisons}

Studies conducted in the 1980s and 1990s suggested that one in four Māori suicide deaths occurred in custody (Justice Department, 1995; Māori Suicide Review Group, 1996). In New Zealand, Māori are over-represented in prison populations, although among prisoners the risk of suicide is similar for Māori and non-Māori (Skegg \& Cox, 1993). The disproportionate number of Māori suicides in custody is accounted for by the higher rate of arrest and incarceration amongst Māori compared to non-Māori (Fergusson, Swain-Campbell, \& Horwood, 2003; Skegg \& Cox, 1993).

\section{DISCUSSION}

Māori suicide rates vary with age. Most $(75 \%)$ Māori suicides occur in Māori younger than 35 years. Suicide is virtually unknown among older Māori with no recent deaths among those aged 60 and older and very few deaths among those aged 45 and older. Compared with nonMāori, Māori youth aged 15-24, have suicide rates which are 2 to 3 times higher. Older Māori have suicide rates lower than those of their non-Māori peers. 
These demographic features of Māori suicide are similar to those reported for indigenous populations for other countries including Australia, Canada, and the USA (Hunter \& Harvey, 2002). In all of these countries the indigenous populations are younger than the non-indigenous populations which have lower suicide rates (Clarke, Frankish, \& Green, 1997). It has been suggested that a cohort effect might account for these observations, whereby young people in populations with a larger fraction of young people could be expected to have more problems than societies with a smaller proportion of young people (Offer \& Schonert-Reichl, 1992).

A central issue raised by these findings is what explains the higher rate of suicide among young Māori. In general, two types of explanations have been proposed in this area: The first of these arguments assumes that the higher rate of suicide among young Māori largely or wholly reflects the disadvantaged status of Māori in the context of New Zealand society. This disadvantaged status is evident in a wide range of areas including health, education, welfare and justice (Ajwani, Blakely, Robson et al., 2003; Blakely, 2002; Durie, 2001; Ferguson, Blakely, Allan et al., 2003; Ministry of Health, 2005; Pomare, Keefe-Ormsby, Ormsby et al., 1995; Public Health Centre, 1995; Te Aho Lawson, 1998). This explanation assumes that when due allowance is made for the disadvantages experienced by Māori rates of suicidal behaviors for Māori are similar to those for nonMāori of similar backgrounds (Fergusson, Swain-Campbell, \& Horwood, 2003).

The alternative explanation assumes that the higher rates of suicide amongst Māori reflect factors that are unique to Māori and to the experience of colonization. For example it has been variously argued that:

There are additional risk factors which apply only to Māori and other indigenous youth. These are the risk factors relevant to cultural alienation, the impact of history through intergenerational modelling and behavioural transfer, and confusion over identity (Te Aho Lawson, 1998).

... suicide cannot be understood only in terms of personal history or individual psychology. The individual is part of an ethnic history and where colonisation has occurred, the scars of oppression and humiliation may become intolerable. In so far as it ends the pain of emptiness and the futility of trying, suicide becomes a solution (Durie, 2001).

While these different perspectives on the origins of the elevated rate of suicide in young Māori are the subject of ongoing debate and speculation, conclusive evidence on which, if either, of these explanatory frameworks accounts for the high rate of Māori suicide is currently lacking. However, it should be noted that similar arguments have been proposed to account for higher rates of suicide among indigenous, compared with non-indigenous, young people in a number of countries including Australia, Canada, and the USA (Hunter \& Harvey, 2002).

Explanations for high youth suicide rates among Māori may partially lie in issues beyond colonization and socioeconomic disadvantage. For example, it has been argued that, in a number of countries, increased rates of youth suicide in the last two decades of the 20th century have reflected an increased tendency for societies to become more individualistic, offering fewer opportunities for social identity and attachment (Eckersley, 2004; Eckersley \& Dear, 2002). Māori, who have traditionally identified themselves as being, first, a member of a collective group, and second, an individual (Robson \& Reid, 2000) may find difficulty in societies which value individualism. 
New Zealand studies have identified children and adolescents who receive child welfare services as a population that has an elevated risk of suicide and suicide attempt, compared with peers who do not receive such services (Smith \& Beautrais, 1999). Within this group Māori children are over-represented and have a high rate of suicidal behavior. It is likely that the higher risk of Māori children in the welfare population results from their exposure to disadvantaged, dysfunctional and adverse childhood environments which are known risk factors for suicidal behavior. This adversity gives rise both to subsequent suicidal behavior (Beautrais, 1999; Fergusson, Woodward, \& Horwood, 2000) and to the problems that account for their need for welfare services. A national program to monitor and provide case management for both Māori and non-Māori suicidal and at-risk young people within the national child welfare service has been developed (Smith \& Beautrais, 1999).

In response to high youth suicide rates in the early 1990s New Zealand developed a National Youth Suicide Prevention Strategy in 1998. The national strategy included two arms: a strategy for Māori youth, and one for mainstream youth. The Māori strategy is "strengths-based" and has a strong emphasis on improving "resiliency." Furthermore, this is accomplished by empowering Māori individuals, families and communities through strengthening cultural identity, and increasing the mainstream population's responsiveness and obligations to Māori (Te Aho Lawson, 1998; Te Puni Kokiri, Ministry of Youth Affairs, \& Ministry of Health, 1998). Suicide prevention programs for Māori youth, instituted as part of the National Youth Suicide Prevention Strategy, have yet to be fully evaluated.

In contrast to youth suicide, where Māori have higher rates than non-Māori, rates of suicide for Māori adults and older adults are lower than, or similar to,
non-Māori rates. There has been relatively little research to examine the extent to which risk and protective factors for adult Māori are similar to, or differ from those for, non-Māori. Of particular interest is the fact that suicide is virtually unknown among older Māori females and occurs in very small numbers (ranging from none to four) each year for Māori males aged 60 and older. The data suggest that culturally specific factors may protect older Māori against suicide.

These observations are consistent with reports from other countries including the USA and Australia (Hunter \& Harvey, 2002), and may reflect the fact that, in these societies, and in Māori society, older people are, generally, more valued, and have meaningful roles and status, than occurs in nonindigenous populations. In addition to age, other factors, which may contribute a protective effect, include spiritual or religious belief, belonging to a family, participation in activities, which maintain culture and cultural traditions, ethnic density and social integration. There is a strong need for research focusing on the reasons for the low suicide rate among older Māori.

There has been relatively little research exploring risk and protective factors for suicidal behavior among Māori, with most New Zealand suicide research focussing on population-based studies. The extent to which findings from these studies apply to Māori is largely unknown. In particular, there have been suggestions that, while Māori may share risk factors with nonMāori, their unique cultural and historical background may generate different risk factors and interpretations for suicidality than for non-Māori in New Zealand (Coupe, 2000; Durie, 2001; Te Aho Lawson, 1998). The Health Research Council has funded studies of risk and protective factors for Māori youth suicide, but findings have not yet been published.

New Zealand is currently developing a national suicide prevention strategy for 
people of all ages. The high suicide rates for Māori youth suggest that a national suicide prevention strategy must include, as a major objective, measures to reduce disparities in youth suicidal behavior. In suicide prevention policy, as for other health policy areas, this is likely to be achieved by partnerships; working with Māori communities to develop appropriate health strategies. These strategies should include participation involving Māori in the development and implementation of a national strategy, and in relevant service delivery and protection (reducing disparities in health outcomes).

These broad policy objectives need to be translated into specific actions, which could be readily implemented. Priorities for Māori include comprehensive evaluation of the strengths-based programmes initiated under the Youth Suicide Prevention Strategy, and additionally, improving identification, service delivery, treatment and management of young Māori with mental health problems. This would indicate developing and improving programs which target at-risk groups of Māori youth including those who access welfare care, those who are not affiliated with either an educational institution or a workplace, those with substance use disorders, and those who have made suicide attempts who are identified at Emergency Departments or General Practitioners surgeries. There is a need to explore the extent to which delivery of services, including mental health services, by Māori service providers is effective in reducing suicidal behaviors. Other areas that need research include the extent to which public health messages (for example, depression awareness or alcohol control campaigns) need to specifically target Māori in order to be effective, improving data-capture systems so high quality ethnicity data are available to inform program development and evaluation, and finally, exploring the extent to which early intervention programs which seek to ameliorate childhood disadvantage and adversity may reduce the number of Māori children exposed to disadvantageous circumstances which are precursors of suicidal behavior.

To conclude, an important decision to be made is in developing a national suicide prevention strategy which centers on whether there should be a single or two separate but linked strategies for all New Zealanders (mainstream population and Māori). The national suicide prevention strategy should be cognisant of, and responsive to, Māori preferences for suicide prevention.

\section{AUTHOR NOTE}

Annette L. Beautrais, Canterbury Suicide Project, Christchurch School of Medicine \& Health Sciences, Christchurch, New Zealand.

David M. Fergusson, Christchurch Health and Development Study, Christchurch School of Medicine and Health Sciences, Christchurch, New Zealand.

Correspondence regarding this article should be addressed to Annette L Beautrais, Canterbury Suicide Project, Christchurch School of Medicine \& Health Sciences, P.O. Box 4345 Christchurch, New Zealand, E-mail: suicide@chmeds. ac.nz.

\section{REFERENCES}

Ajwani, S., Blakely, T., Robson, B., et al. (2003). Decades of disparity: Ethnic mortality trends in New Zealand 1980-1999. Wellington: Ministry of Health. Also available at: www.moh.govt.nz

Beautrais, A. L. (1999). Risk factors for suicide and attempted suicide among young people. Commonwealth Department of Health and Aged Care, National Youth Suicide Prevention Strategy-Setting the evidencebased research agenda for Australia (A literature review) (pp. 113-278). Canberra: Commonwealth of Australia. 
Beautrais, A. L. (2000). Restricting access to means of suicide in New Zealand. A Report Prepared for the Ministry of Health on methods of suicide in New Zealand 1997-1996 (ISBN 0-478-23945-9). Wellington: Ministry of Health.

Beautrais, A. L. (2001). Child and young adolescent suicide in New Zealand. Australian and New Zealand Journal of Psychiatry, 35, 647-653.

Beautrais, A. L. (2003). Suicide in New Zealand I: Time trends and epidemiology. New Zealand Medical Journal, 116. No 1175. Available at: http:// www. nzma.org.nz/journal/116-1175/460/

Beautrais, A. L., Ellis, P., \& Smith, D. A. R. (2001). The incidence of youth at risk of suicide within those accessing child youth and family services. Social Work. Now, August, 8-13.

Blakely, T. (2002). The New Zealand censusmortality study. Socio-economic inequities and adult mortality 1991-1994. Wellington, New Zealand: Ministry of Health.

Clarke, V. A., Frankish, C. J., \& Green, L. W. (1997). Understanding suicide among indigenous adolescents: A review using the PRECEDE model. Injury Prevention, 3, 126-134.

Coupe, N. M. (2000). Māori suicide prevention in New Zealand. Pacific Health Dialogue, 7, 25-28.

Durie, M. H. (2001). Maüri Ora: The dynamics of Māori bealth. Auckland: Oxford, University Press.

Eckersley, R. (2004, 25-26 November 2004). An Australian-Japanese perspective. Cultural dimensions of youth suicide. Paper presented at the Culture, Community and Care Conference, Melbourne.

Eckersley, R., \& Dear, K. (2002). Cultural correlates of youth suicide. Social Science \& Medicine, 55, 18911904.

Ferguson, S., Blakely, T., Allan, B., et al. (2003). Suicide rates in New Zealand. Exploring associations with social and economic factors (10). Wellington, New Zealand: Public Health Consultants, Department of Public Health, Wellington School of Medicine and Health Sciences, University of Otago.

Fergusson, D. M., Swain-Campbell, N., \& Horwood, J. (2003). Ethnicity and criminal convictions: Results of a 21-year longitudinal study. The Australian and New Zealand Journal of Criminology, 36, 354 367.

Fergusson, D. M., Woodward, L. J., \& Horwood, L. J. (2000). Risk factors and life processes associated with the onset of suicidal behavior during adolescence and early adulthood. Psychological Medicine, 30, 23-39.
Hunter, E., \& Harvey, D. (2002). Indigenous suicide in Australia, New Zealand, Canada, and the United States. Emergency Medicine, 14, 14-23.

Justice Department. (1995). Review of suicide prevention in prisons. Wellington: Justice Department.

Māori Suicide Review Group. (1996). Reducing suicide by Māori prison inmates. Department of Corrections and Te Puni Kokori, unpublished report.

Ministry of Health. (2001). Suicide trends in New Zealand 1978-1998. Wellington, New Zealand: New Zealand Health Information Service.

Ministry of Health. (2005). Decades of disparity II. Socioeconomic mortality trends in New Zealand, 1981-1999. Wellington, New Zealand: Ministry of Health. Also available at: www.moh.govt.nz

Neeleman, J., Wilson-Jones, C., \& Wessely, S. (2001). Ethnic density and deliberate self harm: A small area study in south east London. Journal of Epidemiology \& Community Health, 55, 85-90.

Offer, D., \& Schonert-Reichl, K. A. (1992). Debunking the myths of adolescence: Findings from recent research. Journal of the American Academy of Child \& Adolescent Psychiatry, 31, 1003-1014.

Pomare, E., Keefe-Ormsby, V., Ormsby, C., et al. (1995). Hauora: Māori standards of health III-A study of the years 1970-1991. Wellington: Wellington School of Medicine.

Public Health Centre. (1995). Progress on health outcome targets: The state of the public bealth in New Zealand. Wellington: Public Health Commission.

Robson, B. \& Reid, P. (2000). Review of the measurement of ethnicity. Ethnicity matters: Maiori perspectives. Department of Statistics New Zealand, Wellington: Te Ropu Rangahau Hauora a Eru Pomare.

Skegg, K., \& Cox, B. (1993). Suicide in custody: Occurrence in Māori and non-Māori New Zealanders. The New Zealand Medical Journal, 106, $1-4$.

Smith, D. A. R., \& Beautrais, A. L. (1999). Identifying young people at risk of suicide. Social Work Now, 14, 23-34.

Statistics New Zealand. (1998). Demographic trends. Wellington, New Zealand: Statistics New Zealand.

Te Aho Lawson, K. (1998). Kia Piki te Ora o te Taitamariki: A review of evidence. Wellington: Te Puni Kokiri.

Te Puni Kokiri, Ministry of Youth Affairs, \& Ministry of Health. (1998). New Zealand youth suicide prevention strategy: In our hands/Kia Piki te Ora o te Taitamariki. Wellington: Te Puni Kokiri, Ministry of Youth Affairs, Ministry of Health. 